\title{
Normal Torque of the Buccal Surface of Mandibular Teeth and its Relationship with Bracket Positioning: A Study in Normal Occlusion
}

\author{
Marcelo Antonio MESTRINER ${ }^{1}$ \\ Carla ENOKI ${ }^{1}$ \\ José Nelson MUCHA² \\ ${ }^{1}$ Faculty of Dentistry of Ribeirão Preto, University of São Paulo, Ribeirão Preto, SP, Brazil \\ ${ }^{2}$ Department of Orthodontics, Faculty of Dentistry, \\ Fluminense Federal University, NIterói, Rio de Janeiro, RJ, Brazil
}

\begin{abstract}
This study evaluated the degree of buccolingual inclination of mandibular tooth crowns relative to torque. For such purpose, mandibular and maxillary stone casts from 31 Caucasian Brazilian adults with normal occlusion, pleasant facial aspect and no history of previous orthodontic treatment were examined. A custom device was developed for measuring the degree of inclination (torque) of bracket slots of orthodontic appliances relative to the occlusion plane, at three bonding height: standard (center of clinical crown), occlusal (0.5 mm occlusally from standard) and cervical ( $0.5 \mathrm{~mm}$ cervically from standard). Except for the mandibular incisors, which presented a small difference in torque from one another (lingual root torque for central incisors and buccal root torque for lateral incisors), the remaining average values are close to those found in the literature. Due to the convexity of the buccal surface, the 1-mm vertical shift of the brackets from occlusal to cervical affected the values corresponding to the normal torque, in approximately 2 degrees in central and lateral incisors, 3 degrees in canines and 8 degrees in premolars and molars.
\end{abstract}

Key Words: torque, mandibular teeth, buccolingual inclination, bracket slot.

\section{INTRODUCTION}

Despite several innovations incorporated to the original "edgewise" system, its principles and applications remain essentially the same of those introduced by Angle (1) in 1928, when a rectangular wire was associated to a bracket with a rectangular slot, enabling three-dimensional movements.

The force of the torque is probably the most important and powerful force produced by this mechanism (2). Its introduction in Orthodontics has enabled the control of dental movements in the buccolingual direction, which has greatly widened the possibilities of orthodontic treatment.

The clinical parameter for assessing the buccolingual inclination of each tooth is the angle formed by its buccal surface in relation to the occlusal plane (3-5). Because the orthodontist works mainly with dental crowns, they should be the basis of the communication or reference, in the same manner as they are used as a clinical parameter for assessing the treatment prognosis (6).

Whenever conventional brackets are positioned on the buccal surface of the teeth of patients with normal occlusion, in predetermined heights, the inclination of the bracket slot in relation to the occlusal plane indicates the amount of torque necessary to reach the ideal torque for the case.

Regardless of the technique employed for malocclusion correction, in order to obtain a correct or normal buccolingual inclination, it is first necessary to know the average value and the variation limit of

Correspondence: Prof. Marcelo Antonio Mestriner, Curso de Especialização em Ortodontia, Faculdade de Odontologia de Ribeirão Preto, Universidade de São Paulo, Avenida do Café, s/n Monte Alegre, 14040-904 Ribeirão Preto, SP, Brasil. Tel: +55-16-3602-3992. Fax: +5516-3633-0999. e-mail: mestriner@previorto.com.br 
occlusions considered as clinically normal, in case the orthodontist wishes to use this force in a rational and effective manner.

The purpose of this study was to evaluate the degree of buccolingual inclination of mandibular tooth crowns relative to torque.

\section{MATERIAL AND METHODS}

This study used 31 pairs of orthodontic stone casts obtained from Caucasian Brazilian adults (21 females and 10 males) aged 17 years and 2 months to 30 years (mean age 22 years and 1 month), who had never been submitted to orthodontic treatment.

The following criteria were observed for selection of the individuals with normal occlusion; presence of all permanent teeth (third molar was not considered) $(5,6)$; adequate anteroposterior relation of first molars and canines $(5,7)$; slight curve of Spee (7); normal overbite and overjet $(5,8)$; adequate buccolingual inclination of the tooth crowns $(5,7)$; no restorations of buccolingual surface and cusps (5); individuals would not benefit from the orthodontic therapy in terms of function, esthetics and stability (7).

The method used in this study was the determination of the values, variations and means of the inclination of the buccal surface of the mandibular teeth (in the mandibular casts), represented by the degree of inclination (torque) of the bracket slot in relation to 3 bonding heights (Fig. 1): standard (center of the clinical crown or Andrews LE-point) (3), cervical (0.5 mm

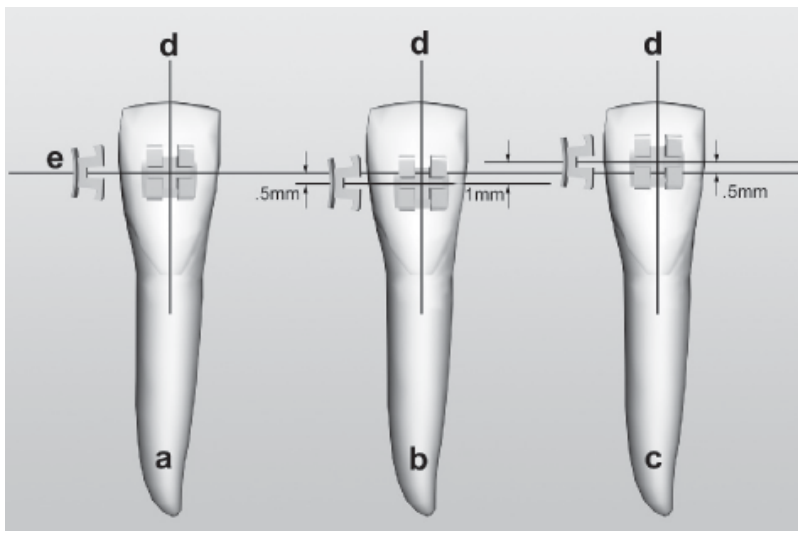

Figure 1. Bonding heights. a: standard (center of clinical crown); b: cervical (0.5 mm cervically to the standard height); c: occlusal ( $0.5 \mathrm{~mm}$ occlusally to the standard height); $\mathrm{d}$ and e: vertical and horizontal reference lines, respectively. cervically to the standard height) and occlusal ( $0.5 \mathrm{~mm}$ occlusally to the standard height).

A longitudinal line parallel to the long axis of the clinical crown (3) and a horizontal line that crossed it passing through Andrews LE-point (3) (determined with the aid of a compass) were drawn for all teeth (Fig. 1). A single set of brackets (Unitek; 3M, St. Paul, MN, USA; standard edgewise dynalock 0.022 X 0.028 inches) was selected and used during the experimental phase. The brackets were bonded using sugar gum developed for indirect bonding technique.

Special care was taken during trimming of the stone casts in a way that the occlusal plane was maintained parallel to the base of the mandibular cast, and was determined with the aid of a custom parallelometer (Fig. 2). This device was developed to determine the degree of inclination of a specific point of the buccal surface and measures the degree of inclination of the bracket slot in relation to the occlusal plane.

For accurate assessment of the degree of inclination of the slot, a rectangular pointer was fabricated from 0.022 X 0.028 orthodontic wire. This pointer attached precisely to the brackets and transferred the inclination from the horizontal plane to the vertical plane. A device was specially developed to accurately measure the degree of inclination (torque) of the vertical segment of the rectangular pointer (Fig. 3).

The degree of inclination of the bracket slot was measured for each tooth in both mandibular hemiarches (right and left). Data were analyzed statistically by Student's t-test at 5\% significance level.

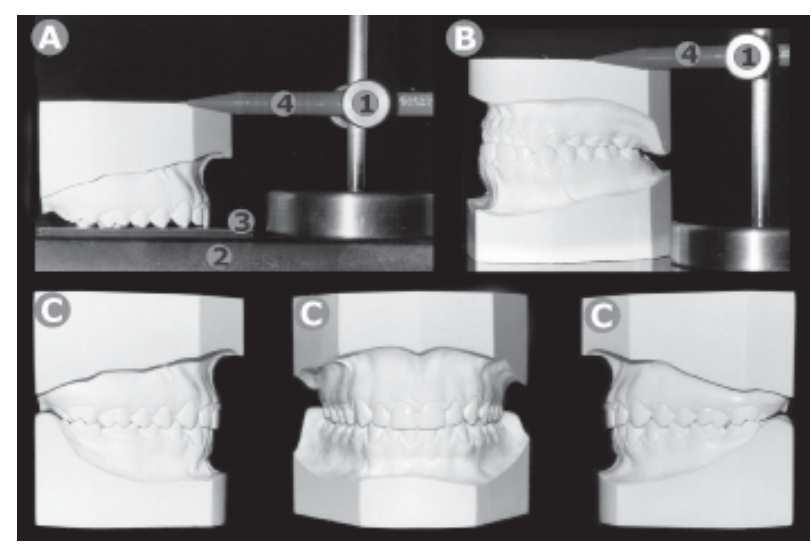

Figure 2. A: Determination of occlusal plane in the maxillary arch. 1 - Parallelometer; 2 - glass plaque; 3 - thin wax plate, 4 - 0.5 $\mathrm{mm}$ propelling pencil. B: Transference of the occlusal plane to the mandibular cast. C: Orthodontic stone casts in centric relation. 


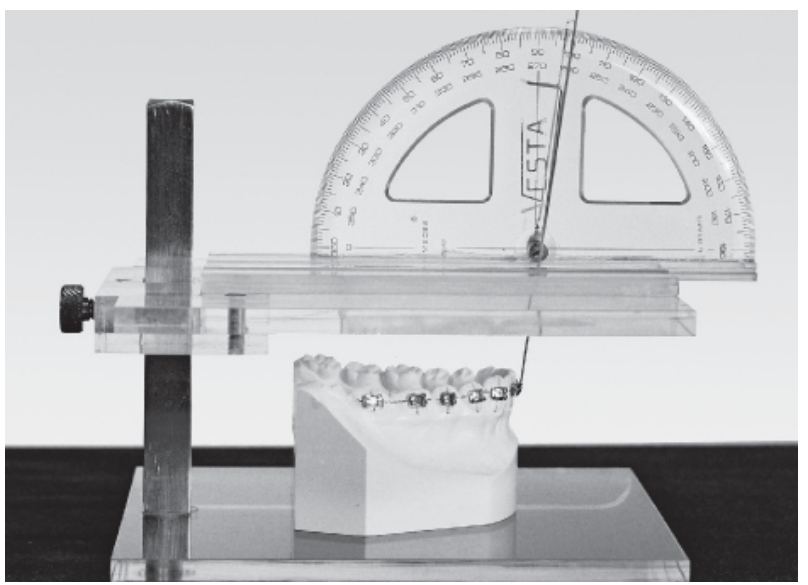

Figure 3. Stone cast positioned for measurement of the inclination of the vertical segment of the rectangular pointer after correct positioning of the protractor to eliminate the parallax effect.

\section{RESULTS AND DISCUSSION}

The results confirmed the reliability of the method used in this study. For the 3 bonding heights evaluated, no significant differences were observed among the values obtained in the mandibular right and left hemiarches ( $p>0.05$ ). Thus, to minimize the possibility of error on determination of the occlusal plane, the arithmetic averages of the values recorded in both hemiarches of each stone cast were obtained and a final value was calculated for each tooth (Table 1).

Determination and quantification of normal buccolingual inclinations of buccal surfaces of several teeth have been widely investigated (5,7,8,9-13). The major challenge has been the development of an ad-

Table 1. Buccolingual degree of inclination (torque) of the mandibular teeth.

\begin{tabular}{lccc}
\hline & Standard & Occlusal & Cervical \\
\hline Central incisor & 2 & 0 & 4 \\
Lateral incisor & -2 & -4 & -1 \\
Canine & -9 & -11 & -7 \\
1st premolar & -16 & -20 & -12 \\
2nd premolar & -22 & -25 & -17 \\
1st molar & -27 & -32 & -23 \\
2nd molar & -32 & -36 & -28 \\
\hline
\end{tabular}

The negative sign (-) indicates a buccal root torque and its absence indicates a lingual root torque. equate methodology that would be capable of yielding trustworthy values with direct clinical application (5).

Questions regarding difficulties of these studies may be summarized as follows: how to determine the inclination of a surface which is mostly irregularly convex; if the degree of inclination is quantitatively represented by an angular value formed by the intersection of two lines, which linear references should be used for determining it; how to apply these values clinically.

Some answers have been proposed to these three questions. First: buccal surface inclination (buccolingual) has been represented by a tangent vertical to this surface (first line of reference ) $(5,8-11,13)$. For this tangent to represent values with clinical application, the chosen tangency point was the one each author considered as representative of the bracket location. In practical terms, the degree of inclination of the bracket slot represents the degree of inclination of this surface from the chosen point of tangency. In the present study, this was determined by the torque-indicating pointer. Second: two solutions have been proposed for determination of the second line of reference, namely a line perpendicular to the occlusal plane $(5,7,8,13)$ or the fixation plane of the brackets (10), and a line representing the long axis of either the tooth (8) or the clinical crown $(9,11)$. The latter does not present a direct clinical application because it only considers dental anatomy without taking into account its relationship with normal occlusion, as well as tooth relationship with the face. Third: the angular values obtained are considered as the amount of torsion that the wire should have or compensation that the brackets should present to produce an ideal force (ideal torque) capable of determining a normal buccolingual positioning of tooth crowns.

The force of the torque may be produced by means of torsion carried out with a rectangular wire or by means of compensation incorporated to the brackets, which nevertheless appears only when the rectangular wire suffers an elastic deformation, as it is attached to the bracket. Its trend to return to the original form results in the creation of a binary situation capable of altering the buccolingual inclination of the tooth. Whenever these procedures (torsion of the wire or compensation in the brackets) are performed to produce forces that determine a normal buccolingual inclination of the teeth, they are referred to as an ideal torque.

Nevertheless, since the force of the torque aims at establishing a normal buccolingual inclination, it is not 
uncommon to use the term "ideal torque" to designate the normal buccolingual inclination of the teeth, as for example: "the ideal torque of the upper central incisor is of 4 degrees", which means that the torsion of the rectangular wire or the corresponding compensation incorporated to the bracket should be of 4 degrees so that this tooth might be positioned with a normal buccolingual inclination. In the present study, the term torque was used to designate both such compensation (incorporated to the wire or to the brackets) and the normal buccolingual inclinations of the teeth.

Regarding the mandibular incisors, the normal torque suggested by the several authors ranges from degree $0(8,14)$ to 1 (buccal root torque) (15), indicating the vertical position of these teeth.

Currently, it is a consensus that the mandibular central and lateral incisors have the same torque. Nevertheless, it has been demonstrated that there is a small variation between the torque of these two teeth $(5,10,13)$ (Table 2). This study showed a difference of at least 4 degrees between the torque of the mandibular central and lateral incisors, independently of the bonding height (Table 1). In view of the values obtained, it could have been mistakenly stated that the mandibular lateral incisor (buccal root torque) is more vertical than the mandibular central incisor (lingual root torque).

The fact that the lateral incisor presents a buccal root torque in relation to the lateral incisor for the same bonding height simply reflects an anatomical difference of the buccal surface. It would also be incorrect to assume that the root of the lateral incisor is more in buccoversion than the central incisor because there are factors such as the variations between the angle formed by the crown and the root (9).

Although this conclusion could cause surprise, its explanation is quite simple. The buccolingual diameter of the mandibular lateral incisor is slightly greater than that of the mandibular central incisor $(0.4 \mathrm{~mm}$ on average) (16-17). This anatomical difference leads the tangent of the buccal surface of the lateral incisor to assume a more vertical position compared to that of the central incisor (Fig. 4).

Buccal root torque considered as being progressive to the mandibular posterior teeth from the canines $(5,18)$ was confirmed in this study, regardless of the bonding height (Table 1). This increase was expressed in a more uniform manner in the cervical heght, where it was observed an arithmetic progression with an

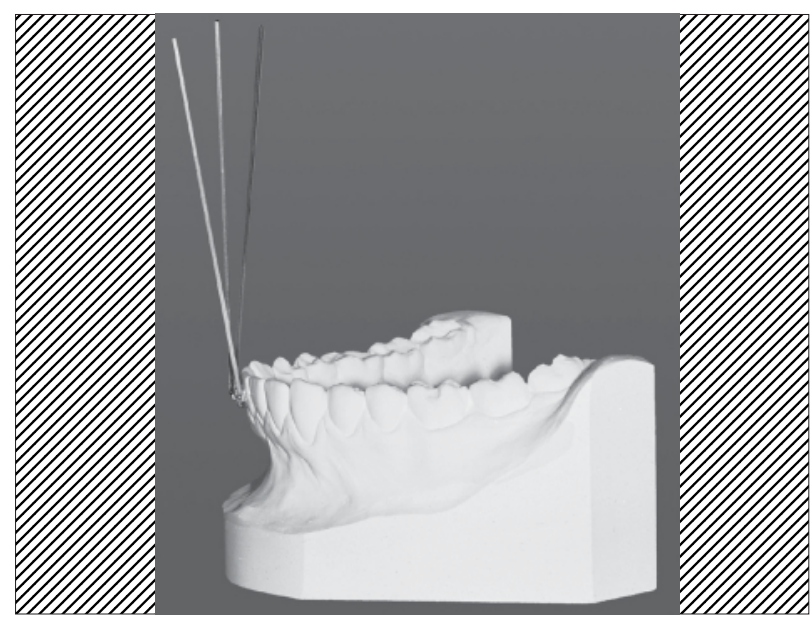

Figure 4. Lateral view of the stone cast showing a 9 degreedifference between central and lateral incisors and lateral incisor and canine. Progressive torque starts from the central incisors.

Table 2. Torque means ( $\pm \mathrm{SD}$ ) reported by different authors in comparison to those found in the present study.

\begin{tabular}{lcccrr}
\hline & Vardimon*(13) & Vardimon**(13) & Dellinger***(10) & Uður*(5) & This study* \\
\hline Central incisor & $1.26 \pm 5.41$ & $2.24 \pm 5.91$ & $-0.80 \pm 4.32$ & $0.92 \pm 6.01$ & $2.03 \pm 5.30$ \\
Lateral incisor & $-1.35 \pm 5.10$ & $-0.90 \pm 6.00$ & $-2.80 \pm 5.01$ & $-3.05 \pm 5.23$ & $-2.34 \pm 4.70$ \\
Canine & $-9.00 \pm 3.77$ & $-9.69 \pm 4.43$ & $-12.70 \pm 4.51$ & $-11.35 \pm 5.02$ & $-8.90 \pm 4.92$ \\
1st premolar & $-15.90 \pm 4.36$ & $-16.40 \pm 5.34$ & $-18.60 \pm 5.66$ & $-20.32 \pm 5.52$ & $-16.42 \pm 5.46$ \\
2nd premolar & $-21.16 \pm 5.15$ & $-22.53 \pm 6.04$ & $-22.48 \pm 5.17$ & $-26.50 \pm 5.12$ & $-21.57 \pm 6.09$ \\
1st molar & $-26.00 \pm 4.60$ & $-26.89 \pm 5.48$ & $-29.60 \pm 6.82$ & $-34.15 \pm 3.79$ & $-27.45 \pm 8.04$ \\
2nd molar & $-32.82 \pm 4.92$ & $-36.41 \pm 7.39$ & $-30.46 \pm 6.84$ & $---5^{*}$ & $-31.70 \pm 7.18$ \\
\hline
\end{tabular}

* = Normal occlusion, without orthodontic treatment; $* *=$ Normal occlusion and set-ups without extraction; *** = Set-ups with and without extractions. Torque means presented as the findings of this study (last column) correspond to the standard bonding height. 
increment of approximately 5 degrees for adjacent teeth. This characteristic actually started to be observed from the mandibular central incisor and not only from the canine, denoting a progressive torque in the whole mandibular arch from anterior to posterior (Table 1 and Fig. 4). This is in agreement with the findings of previous studies $(5,10,13)$ (Table 2). The importance of knowing the average torque for each tooth is still unclear. Its major applicability is to be used as an initial reference point for maintenance or correction of the axial inclination (buccolingual) of the teeth.

The values in Table 3 reflect more accurate data, obtained by means of a more consistent sample and techniques. We can notice a great similarity between the values obtained in these studies and the present work.

Vardimon (13), Dellinger (10) and Ugur (5) have also found differences in torque between the central and lateral mandibular incisors, respectively: 2.61 and 3.14, 3.60 and 3.97 degrees. Nevertheless, these differences were slightly greater in the present work: 4.01 occlusal, 4.37 standard and 4.58 cervical (Table 1 ). This might be attributed to two factors: the slight crowding of the mandibular incisors observed in the studied populations and morphological differences in dental anatomy inherent to the distinct ethnic groups evaluated. The slight anteroinferior crowding is not consistent with the findings by Vardimon (13), who reporetd a 2.61-degree difference in torque for teeth of orthodontic patients with normal occlusion and a 3.14-degree difference when they are associated to set-up (Table 2). Difference in torque should decrease when the group is associated with set-up (theoretically without anteroinferior crowding) with the normal occlusion group (where up to $1 \mathrm{~mm}$ crowding was allowed). Morphological differences in

Table 3. Differences between the buccolingual degrees of inclination (torque) of the mandibular teeth recorded at the occlusal and cervical bonding heights.

\begin{tabular}{lccc}
\hline & Means $( \pm$ SD) & Maximum & Minimum \\
\hline Central incisor & $3.34 \pm 1.55$ & 7.63 & 0.75 \\
Lateral incisor & $2.77 \pm 1.45$ & 5.50 & 0.50 \\
Canine & $3.75 \pm 1.89$ & 9.75 & 8.88 \\
1st premolar & $7.73 \pm 2.39$ & 14.63 & 4.25 \\
2nd premolar & $8.41 \pm 2.68$ & 14.88 & 4.38 \\
1st molar & $8.44 \pm 2.45$ & 13.13 & 3.63 \\
2nd molar & $7.70 \pm 2.78$ & 12.88 & 1.25 \\
\hline
\end{tabular}

dental anatomy find some support because the difference of buccolingual diameter between the mandibular incisors suffers considerable variations (from 0.1 to 0.4 $\mathrm{mm})$ depending on the sample studied $(16,17)$.

The normal variation limit, represented by the standard deviation of the buccolingual inclination, tends to increase from mesial to distal, being approximately 5 degrees for mandibular incisors and canines, 6 degrees for premolars and 7 degrees for molars (Table 2). Nevertheless, the most significant information is perhaps the great variation found in the normal occlusion sample. Even if this is a sample constituted by a selected and rare group of individuals, the torque of incisors and canines, for example, ranged from negative (buccal root torque) to positive values (lingual root torque).

Table 3 illustrates the mean torque variations between the occlusal and cervical bonding heights (total variation of $1 \mathrm{~mm}$ ). These variations only reflect buccal surface anatomy, not being influenced by the degree of buccolingual inclination of the tooth as a whole (Fig. 5). The approximate average of the torque variation between the bonding extremes (Table 3) revealed that the mandibular incisors and canines present a slightly convex surface ( 3 and 4 degrees respectively) compared to mandibular premolars and molars (8 degrees). This variation may be even larger clinically because factors such as adaptation of bands and brackets, welding of the brackets and their cementation or bonding may also contribute to a higher degree of variation.

For any type of fixed appliance, care must be taken regarding the correct positioning of the brackets and tubes. This is crucial for straight arch techniques because it can affect the amount of torque transmitted to the tooth $(3,9,10-12)$. Orthodontists must be aware

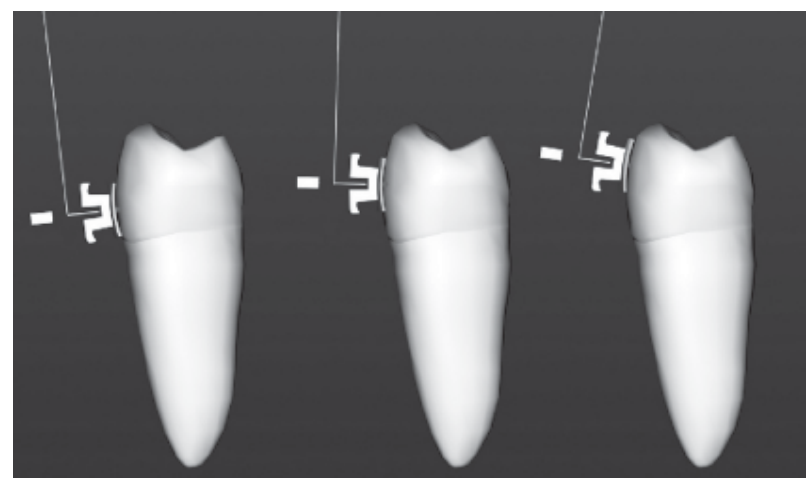

Figure 5. Torque variation according to buccal surface anatomy. 
that they are treating individuals and not statistical data and thus the amplitude of sample variation is clinically more significant than its standard deviation.

The following conclusions may de drawn: 1 Except for the mandibular incisors, which had a small difference in torque from each other (lingual root torque for central incisors and buccal root torque for lateral incisors), the other values were close to those found in the literature. 2 - Torque increased progressively in the three bonding heights for the mandibular central incisors, but the cervical height showed a more uniform pattern, with an average increase of nearly 5 degrees for adjacent teeth. 3 - The vertical shift of orthodontic brackets, from occlusal to cervical, affected normal torque values as follows: a) torque of mandibular incisors tended towards positive values (lingual root torque), as the bracket shifted from occlusal to cervical; b) torque of posterior teeth tended towards negative values (buccal root torque) at cervical heights compared to occlusal heights; c) the more cervical the position of the orthodontic appliance, the lesser the need for buccal root torque application. 4 - Average variations between the bonding extremes, i.e., occlusal and cervical, were: a) central and lateral incisors: approximately 2 degrees; b) canines: approximately 3 degrees; c) premolars and molars: approximately 8 degrees.

\section{RESUMO}

Este estudo avaliou o grau de inclinação vestíbulo-lingual de coroas dentais de dentes inferiores em relação ao torque. Foram obtidos modelos de gesso das arcadas superiores e inferiores de 31 adultos brasileiros, brancos com oclusão normal e estética facial agradável, que nunca haviam sido submetidos a tratamento ortodôntico. Foi desenvolvido um dispositivo capaz de medir o grau de inclinação do encaixe retangular do bráquete em relação ao plano oclusal, em três alturas de colagem: padrão (centro da coroa clínica); oclusal (deslocado $0.5 \mathrm{~mm}$ para oclusal em relação à posição padrão) e cervical ( $0.5 \mathrm{~mm}$ para cervical em relação à posição padrão). Com exceção dos incisivos inferiores, que apresentaram pequena diferença de torque entre si (centrais com torque lingual de raiz e laterais com torque vestibular de raiz), os demais valores médios estão próximos aos encontrados na literatura. A variação vertical dos bráquetes em $1.0 \mathrm{~mm}$ (de oclusal para cervical) determinou, devido à convexidade da face vestibular, pequenas variações de torque para incisivos e caninos e valores mais acentuados para pré-molares e molares (em média 2, 3 e 8 graus, respectivamente).

\section{ACKNOWLEDGEMENTS}

This research was part of the requirements to grant a Master's degree in dentistry from the Postgraduate Program in Orthodontics of the Faculty of Dentistry of the Federal University of Rio de Janeiro (UFRJ) and was supported by CAPES.

\section{REFERENCES}

1. Angle EH. The latest and best in orthodontic mechanism. Dent Cosmos 1928;70:1143-1158.

2. Kang BS, Baek SH, Mah J, Yang WS. Three-dimensional relationship between the critical contact angle and the torque angle. Am J Orthod Dentofac Orthop 2003;123:6473.

3. Andrews LF. The straight-wire appliance explained and compared. J Clin Orthod 1976;10:174-195.

4. Ross VA, Isaacson RJ, Germane N, Rubenstein LK. Influence of vertical growth pattern on faciolingual inclination and treatment mechanics. Am J Orthod Dentofac Orthop 1990;98:422-429.

5. Uður T, Yukay F. Normal faciolingual inclinations of tooth crowns compared with treatment groups of standard and pretorgued brackets. Am J Orthod Dentofac Orthop 1997;112:50-57.

6. Peck S, Peck H. Crown dimensions and mandibular incisor alignment. Angle Orthod 1972;42:149-153.

7. Andrews LF. The six keys to normal occlusion. Am J Orthod 1972;62:296-309.

8. Ricketts RM. Provocations and perceptions in craniofacial orthopedics. Denver: Rocky Mountain Orthodontics; 1989.

9. Bryant RM, Sadowsky PL, Dent M, Hazelrig JB. Variability in three morphologic features of the permanent maxillary central incisor. Am J Orthod 1984;86:25-32.

10. Dellinger EL. A scientific assessment of the straight-wire appliance. Am J Orthod 1978;73:290-299.

11. Germane N, Bentley BE, Isaacson RJ. Three biologic variables modifying faciolingual tooth angulation by straight-wire appliances. Am J Orthod Dentofac Orthop 1989;96:312-319.

12. Germane N, Bentley BE, Isaacson RJ. The morphology of cuspids in relation to preadjusted appliances. Angle Orthod 1990;60:49-54

13. Vardimon AD, Lambertz W. Statistical evaluation of torque angles in reference to straight-wire appliance (SWA) theories. Am J Orthod 1986;89:56-66.

14. Hocevar RA. Begg-edgewise diagnosis-determined totally individualized orthodontic technique: foundations, description, and rationale. Am J Orthod 1985;88:31-46.

15. Miethke RR. Third order tooth movements with straight wire appliances. Influence of vestibular tooth crown morphology in the vertical plane. J Orofac Orthop 1997; 58:186-197.

16. Bishara SE, Jakobsen JR, Abdallah EM, Garcia AF. Comparisons of mesiodistal and buccolingual crown dimensions of the permanent teeth in three populations from Egypt, Mexico and the United States. Am J Orthod Dentofac Orthop 1989;96:416-422.

17. Smith RJ, Davidson WM, Gipe DP. Incisors shape and incisors crowding: a re-evaluation of the Peck and Peck ratio. Am J Orthod 1982;83:231-235.

18. Roth RH. The straight-wire appliance 17 years later. J Clin Orthod 1987;21:632-642. 